\title{
INTXAURBE VITORICA, José Ramón, GONZÁLEZ HIDALGO, Eloísa y URRUTIA ASUA, Gorka (2019). Informe sobre la injusticia padecida por concejales que sufrieron violencia de persecución (1991-2011), Vitoria-Gasteiz: Gobierno Vasco. 43 páginas (ISBN: 978-84-457-3465-0)
}

doi: http://dx.doi.org/10.18543/djhr-4-2019pp260-262

"El Informe sobre la injusticia padecida por concejales que sufrieron violencia de persecución (1991-2011)" es un trabajo en el que se abordan los aspectos más relevantes sobre la realidad que tuvieron que vivir las personas que ejerciendo su responsabilidad de representación municipal se encontraron con la intimidación por parte de ETA. Concejales de diverso signo político vieron condicionada su cotidianidad por ejercer un derecho humano como el de la participación política. Esta situación no solamente afectó a su quehacer diario como representantes municipales, trascendió ese ámbito y tuvo una afectación directa en sus relaciones familiares, sociales y laborales. Esta realidad es la que recoge la publicación de José Ramón Intxaurbe Vitorica, Eloísa González Hidalgo y Gorka Urrutia Asua. Los tres, investigadores del Instituto de derechos humanos Pedro Arrupe de la Universidad de Deusto, desarrollan el encargo realizado por la Secretaría General de Derechos humanos, Convivencia y Cooperación del Gobierno Vasco en las 43 páginas del informe.

Este informe parte de un estudio previo en el que se abordó la figura de la persona amenazada. En dicho informe ${ }^{1}$, del año 2016, se acotó el estudio a las personas que habían recibido algún tipo protección mediante la figura de escolta o guardaespaldas. De entre los grupos estudiados en dicho informe, el de los concejales era uno de ellos y es precisamente en el que se profundiza en este trabajo. Debido al periodo temporal acotado, las legislaturas municipales contempladas son las cuarta, quinta, sexta, séptima y octava. Los objetivos planteados al inicio del trabajo son los dos siguientes:

1. Ofrecer una descripción cuantitativa y cualitativa del sufrimiento injusto provocado a concejales que sufrieron amenazas y acoso directo en el marco de la violencia de ETA.

1 Intxaurbe Vitorica, José Ramón, Urrutia Asua, Gorka y Ruiz Vieytez, Eduardo J.; Informe sobre la injusticia padecida por las personas amenazadas por ETA (1990-2011) de 31 de marzo de 2016. 
2. Extraer conclusiones en materia de clarificación de derechos humanos vulnerados mediante la amenaza y en materia de reparación a sus víctimas.

La publicación comienza con una contextualización del periodo temporal objeto de estudio que sirve para ubicar a quien lo lee. En las primeras páginas del trabajo se recogen los aspectos más destacables de esa época, de tal manera que de una forma muy concreta se consigue una adecuada ubicación temporal. Se trata, como se resalta, de un periodo especial en el que ETA utilizó la violencia como componente de persecución del cuerpo social que no comulgaba con sus planteamientos. La ponencia Oldartzen y el concepto de socialización del sufrimiento son representativos de este planteamiento con el que, entre otros colectivos, el de los representantes políticos a nivel municipal tuvieron que sufrirlo en primera persona.

El grueso del trabajo se divide en dos grandes partes. La primera, con una vertiente de carácter cuantitativo y la segunda, en la que se recoge la parte central del estudio, la de carácter cualitativo, basada en el trabajo de entrevistas en profundidad realizado a personas que sufrieron la violencia de ETA y se vieron obligadas a contar con escolta.

En la primera parte de este componente central del trabajo, la cuantitativa, se exponen datos sobre indicadores que nos acercan a la realidad objeto de estudio tales como el número de cargos y miembros de partidos políticos con escolta y el número de años que tuvieron que vivir con ese operativo de protección, datos sobre los resultados de las elecciones municipales en la Comunidad Autónoma de Euskadi en cada uno de los periodos electorales entre 1991 y 2011. Por último, también se ofrece la información sobre la cronología de atentados mortales de ETA contra concejales durante ese periodo de tiempo.

El grueso de este componente central se detiene en las historias de vida de un conjunto de casos significativos. Las particularidades y vivencias de esta situación contadas por sus protagonistas permiten a los autores del trabajo indagar en el impacto que la violencia de ETA tuvo sobre estas personas: la coacción permanente y sostenida en el tiempo, los ataques contra algunas de estas personas, así como sus bienes, la afectación que dicha coacción tuvo sobre la libertad y seguridad de los concejales y las consecuencias que tuvo sobre su entorno familiar y sociolaboral. Todo ello se estructura en diversos subapartados que permite al lector acercarse a esa situación, a través del análisis de los autores y de los testimonios de las víctimas que han participado en el estudio, todas ellas concejales del ámbito territorial de la Comunidad Autónoma de Euskadi. 
En el primero de los subapartados se desgrana los motivos que llevaron a estar personas a participar políticamente en su compromiso con el municipio y su vecindario. En el segundo, la atención se centra en la dificultad que ese compromiso entraña cuando la participación política se realiza en el entorno más cercano a la vida de la ciudadanía y esta se produce en un contexto bajo la amenazada terrorista de ETA. El tercer subapartado es el que aborda, desde una perspectiva temporal, las diferentes etapas de acoso e intimidación (con la dificultad para completar listas electorales, la inflexión producida a partir de la ponencia Oldartzen, el alto el fuego de 1998 y su posterior ruptura, y el periodo posterior a la Ley de Partidos Políticos). El siguiente subapartado desgrana las consecuencias más significativas del acoso que sufrió este colectivo, desde el aislamiento al que se vieron sometidos socialmente hasta cómo todo esto afectó a sus familias y en su entorno sociolaboral. Por último, el componente cualitativo del trabajo recoge algunos de los elementos más destacados por los concejales víctimas de persecución en clave de memoria reparadora y cómo se pueden extraer enseñanzas para el conjunto de la sociedad.

El informe se cierra con dos capítulos concluyentes. Uno de ellos en el que se hace una enumeración y calificación de las principales vulneraciones de derechos humanos detectadas en este tema. Se trata de un apartado lógico, que expone con claridad y de manera resumida los aspectos detectados en los dos capítulos anteriores. El otro, en el que se recogen las valoraciones finales del estudio, es en el que se concluye el trabajo a partir de la tríada de verdad, justicia y reparación. En esta parte final se recogen una serie de propuestas en clave de futuro con las que recoger la memoria sobre la exclusión y el exterminio de la diferencia que se produjo durante ese periodo, la reparación a través de la deuda que tenemos como sociedad para preservar la pluralidad innata de cualquier democracia y, por último, en clave de reconciliación y cohesión social, el compromiso por no repetir situaciones como las expuestas y analizadas en este trabajo.

En definitiva, se trata de un trabajo de investigación riguroso, de una temática imprescindible para conocer nuestro pasado más reciente y ser conscientes del sufrimiento que tuvieron que soportar un muy buen número de conciudadanos. Tal y como concluye este trabajo, que sirva para contribuir a una sociedad más cohesionada y respetuosa y comprometida con el pluralismo democrático.

Liliana Zambrano Quintero Investigadora en paz y conflictos 


\section{Copyright}

Deusto Journal of Human Rights / Revista Deusto de Derechos Humanos is an Open Access journal; which means that it is free for full and immediate access, reading, search, download, distribution, and reuse in any medium only for non-commercial purposes and in accordance with any applicable copyright legislation, without prior permission from the copyright holder (University of Deusto) or the author; provided the original work and publication source are properly cited (Issue number, year, pages and DOI if applicable) and any changes to the original are clearly indicated. Any other use of its content in any medium or format, now known or developed in the future, requires prior written permission of the copyright holder.

\section{Derechos de autoría}

Deusto Journal of Human Rights / Revista Deusto de Derechos Humanos es una revista de Acceso Abierto; lo que significa que es de libre acceso en su integridad inmediatamente después de la publicación de cada número. Se permite su lectura, la búsqueda, descarga, distribución y reutilización en cualquier tipo de soporte sólo para fines no comerciales y según lo previsto por la ley; sin la previa autorización de la Editorial (Universidad de Deusto) o la persona autora, siempre que la obra original sea debidamente citada (número, año, páginas y DOI si procede) y cualquier cambio en el original esté claramente indicado. Cualquier otro uso de su contenido en cualquier medio o formato, ahora conocido o desarrollado en el futuro, requiere el permiso previo por escrito de la persona titular de los derechos de autoría. 